\title{
Audio- Drama Nursing Intervention Utilizing Peer Education on Menstrual Hygiene and Sickness Management among Blind Adolescents
}

\author{
Sabah Ramadan Hussein Ahmed ${ }^{1}$, Safaa Gaber Salem ${ }^{2}$, Reda El feshawy ${ }^{3}$, \\ Asmaa Elsayed Farid Amr ${ }^{4}$
}

\author{
${ }^{1}$ Assistant Professors of Maternal and Newborn Health Nursing, Faculty of Nursing, Helwan \\ University \\ ${ }^{2}$ Lecturer of Maternal and Newborn Health Nursing, Faculty of Nursing, Menoufia University \\ ${ }^{3}$ Lecturer of Pediatric Nursing Department, Faculty of Nursing, Menoufia University \\ ${ }^{4}$ Lecturer of Family and Community Health Nursing, Faculty of Nursing, Menoufia University
}

\begin{abstract}
:
Adolescence is a critical developmental stage. Blind adolescent girls are a group of disabled girls who needs a special care specifically during the menstruation.The study aimed to examine the effect of audio- drama nursing intervention utilizingpeer education on menstrual hygiene and sickness management among blind adolescents. Design: Quasi- experimental design (pre and posttest) was used to accomplish the present study. Setting: Al Noor institute for visually impaired students at Shebein El-kom City in Menoufia Governorate, Egypt. Subjects: A Convenient sample of 40 blind girls aged between (12-18years) was recruited in this study. Tools: four instruments were used for data collection; I: Structured interviewing questionnaire which consist of two parts; first part:Socio-demographic data; second part: Menstrual data. II: An interviewing questionnaire on knowledge about menstruation; Knowledge about menstrual hygiene questionnaire; andKnowledge about management of menstrual sickness questionnaire. III: Non - observational checklist on practice of menstrual hygiene and management of menstrual sickness. IV: An interviewing questionnaire on satisfaction level. Results: There were lack knowledge and practices regarding menstruation before implementing the audio drama nursing intervention using peer education sessions. Also, there were an improvement and highly statistically significant differences in the totalscores of knowledge and practices of blind adolescent girls regarding menstruation after provision of the audio drama nursing intervention using peer education $(\mathrm{P}<0.001)$. Conclusion: The audio drama nursing intervention using peer education were effective in the improvement of the blind adolescent girls' knowledge and practices regarding menstrual hygiene and menstrual sickness management. Recommendation: Continues health education programs should be applied to raise the awareness of blind adolescent girls regarding menstruation in different setting.
\end{abstract}

Keywords: Audio- Drama Nursing Intervention, Peer Education, Menstrual Hygiene, Menstrual Sickness Management, Blind Adolescent. 


\section{Introduction:}

Adolescence is a critical developmental stage; it is described as a spurt in physical, endocrinal, behavioral, and mental development with a renovation from comprehensive dependence to relative independence $^{(1)}$. The adolescent stage in a girl is known as a special period, which indicates transition from the girlhood to the womanhood, the onset of menarche is one of the main physiological changes that take place in adolescent girl's life ${ }^{(2)}$.The World Health Organization (WHO) defines adolescents as persons between the age 10 and 19 years. Adolescence in girls has been known as a special stage in their life cycle that needs special attention $^{(3)}$.Globally, adolescents consist of $20 \%$ of the world population and living mostly $(85 \%)$ in developing societies ${ }^{(4)}$.Approximately $52 \%$ of the female population ( $26 \%$ of the overall population) in the age of reproduction ${ }^{(5)}$.

Menstruation is an essential part of human natural life, definitely of human existence. The menstrual cycle is an exact important indicator of adolescent' reproductive health ${ }^{(2)}$.Menstruation is the periodic vaginal bleeding that happens through the shedding of the uterine mucosa is one of the puberty signs; every mature adolescent girl menstruates 3-5 days on the usual (minimum 2 days, maximum 7 days) every month till menopause. Culturally, talk on menstruation is often shrouded in secrecy. Although menstruation is a normal physiological process, many adolescents hardly have any knowledge regarding normal and abnormal menstruation and do little to alleviate the symptoms ${ }^{(6)}$.Several countries have traditionally believed strong taboos associated with menstruation. This sequentially may influence how adolescent girls manage their menstrual sickness according to their beliefs, attitudes and/or a lack of precise information ${ }^{(7)}$.

Blindness is considered as the most traumatic physical disability. All individuals with disability may be affected by this lifelong cycle of stigma and prejudice, especially blind adolescent girls, are particularly at risk. The blind adolescent girls need support in personnel activities. It is very hard for blind girls to handle their menstruations; they have limitations to make their activities and also lack the ability to learn from observation and performing self-care activitiesdue to loss of vision $^{(2)}$.The WHO defines blindness as a corrected visual acuity in the better eye of a lesser than 3/60, and severe visual impairment as a corrected acuity in the better eye of lesser than $6 / 60$. 
Childhood blindness is a group of diseases if untreated, cause blindness or severe visual impairment in childhood or early adolescence which expected to be permanent later in life. Reduced or absent eyesight can have significant and longlasting impacts on all aspects of life ${ }^{(8)}$.The causes of blindness are unaddressed refractive error, cataract, corneal opacities, glaucoma, trachoma and diabetic retinopathy ${ }^{(9)}$.WHO's effort is directed by the WHO recommendations based on the world report on vision 2019 and the perseverance on 'integrated, peoplecentered eye care, was adopted at $73^{\text {rd }}$ World Health Assembly in $2020^{(10)}$.

Globally, Blindness and vision impairment affect at least 2.2 billion individuals around the world. The prevalence of blindness in children in low-income societies is 1.5 per 1000 children, while in high-income societies is around 0.3 per 1000 children. Worldwide, the total number of blind children is approximately 1.4 million, around three-quarters of them existing in the poorest regions of Africa and Asia ${ }^{(8)}$.Ninety percent of the world's blind persons existing in developing countries, around $7 \%$ of these children are adolescents ${ }^{(2)}$.

Menstrual hygiene is the maintenance of hygiene involving dailybath, correct way to use sanitary pad, cleaning perineal area for the period of menstruation to help in reproductive health maintenance and illness prevention. Blind girls have the probability being high risk for reproductive sickness; menstrual hygiene is very important approach to maintenance of normal reproductive health and prevention urinary tract infection among them ${ }^{(11)}$. The practices of menstrualhygieneof adolescent girls can have a great impact on their health ${ }^{(12)}$.Good menstrual hygienic practices subsequently decrease the prevalence of gynecological problems ${ }^{(13)}$. Worldwide, every year approximately 10 $\%$ of females have genital infections comprising urinary tract infections and vaginitis, and $75 \%$ of females have a history of a genital infection. The common risk factor for vaginal infections is poor menstrual hygiene ${ }^{(14)}$.Unfortunately; $90.5 \%$ of girls are unsuccessfully meet the criteria for sufficient menstrual hygienic practices ${ }^{(15)}$.

Menstrual sickness is a collection of physical and emotional symptoms related to a females' menstrual cycle. The symptoms may be related to water retention such as mood changes, dysmenorrhea and breast pain, pain in the back, nausea, polymenorhhoea or oligomenorrhoea menstruation ${ }^{(11)}$.Other 
symptoms are bloating, breast tenderness, clumsiness, headache, confusion, difficulty in concentrating, fatigue, sadness, tension, anxiety, mood swings, and irritable behavior and sleep problems. The symptoms surprise during another half of the menstrual cycle and dissolve 1 - 2 days after the beginning of menstruation $95 \%$ of girls in Ghana $86 \%$ and $53 \%$ of girls in Garissa and Nairobi (respectively), 51\% of girls In Ethiopia and 7\% of girls In Malawi miss school due to menstrual Sickness ${ }^{(16)}$.Management of menstrual symptomscan be pharmacological and nonpharmacological approaches ${ }^{(17)}$.

Menstruation is a normal growth process related to the reproductive cycle of adolescent girls. It is not a disease, but if not appropriately managed it can cause health problems ${ }^{(18)}$.Worldwide, $74.3 \%$ of adolescent girls have health problems during menstruation as back pain $(54.5 \%)$ mood change (35.3\%) irregular menstruation $(20.7 \%)$, headache $(15.1 \%)$ menstrual flow excess (14.9\%) sleep disorder $(6 \%)^{(19)}$.Dysmenorrhea is defined as menstruation pain and considered the most common cause of visit gynecological doctors that severely affects the daily activities and quality of life of adolescents girls $(\mathrm{QOL})^{(20)}$.Dysmenorrhea rates reaching from $16 \%$ to $91 \%$ (adolescent girls havehigher rates $)^{(21)}$. The prevalence of abdominal spasm (70.4\%), back pain (69.7\%) and dysmenorrhea (63\%) ${ }^{(22)}$.Jeyanthi ,2017 found that, All of the blind adolescent girls' had minor health problems during menstruation. Most of them $(63.33 \%)$ experienced of dysmenorrhea and $70 \%, 63.33 \%$ of them have back pain in control and study groups respectively ${ }^{(11)}$.

A peer is an individual who has the same characteristics with another individual as in age, background, culture or interests, and social status to educate, inform and empower each other's choices which supplemented their knowledge with correct and attractive information. It is significantly better to instructthe adolescents, peers play an important role in the social development of adolescents, peer education is now considered as a significant strategy of health promotion in adolescents. Peer education is defined as a strategy of providing knowledge that enhances social learning and psychosocial development which is considered as effective strategy for training adolescents ${ }^{(23)}$.Peer educators are perceived as opinion leaders and respected by other adolescents. These leaders espouse a definite lifestyle and their peers desire to emulate them ${ }^{(24)}$.Peer education comprised the structure 
of the objects that would be introduced to the adolescents and the principles of education ${ }^{(25)}$.Peer education reveals the adequacy in knowledge and practices ofgroup education than single one ${ }^{(26)}$.

Audio drama defined as auditory performance projecting a series of actions and education that are highly dramatized and organized ${ }^{(11)}$.It'svaluableinsaving timeand can be played repetitively to attain appropriate outcomes ${ }^{(27)}$.Audio drama is a technique of telling data through sound. It is purely sound performance broadcast on audio media, for example tape or $\mathrm{CD}$ without visual component. Audio drama rest on information flow, music and sound effects .It is auditory dimension but have equal effect of visual force in the psychological dimension ${ }^{(28)}$.Audio drama can provide a blind adolescents audience with the similar level of presence as an audiovisual stimulus does among sighted individual. ${ }^{(29)}$.As one blind person expressed it, "rather than just listening to the data, Audio drama makes it feel more real" $^{(30)}$.

Nurses can play an active role in equipping blind adolescent girls with sufficient knowledge and practices on hygiene and care during menstruation to improve their health $^{(18)}$.It is a basic requirement for a satisfied life and promoting self-esteem in blind adolescent girls. Nursing education about menstrual hygiene sickness management is a vital aspect of health education of blind adolescent girls as patterns that persist into adult life ${ }^{(6)}$.

\section{Significance of the study}

Blind adolescent girls' needs have been widely neglected and poorly addressed. The increasing needs for menstrual hygiene maintenance for blind adolescent girls constantly a challenge ${ }^{(11)}$.Hence, precise actions should be taken to get blind adolescent girls the better health education on menstrual hygiene and care ${ }^{(31)}$.The early education should be delivered for imparting sufficient knowledge and skills on menstrual hygiene to assist them to perform it independently ${ }^{(2)}$.Lack of menstrual hygiene can facilitate the spread of infections( including harmful anal bacteria, which can transmitted to the urinary tract; also, blind adolescent girls at more risk of UTI, toxic shock syndrome, pelvic inflammatory disease, fibroids, endometriosis, ovarian cancer, pubic lice and scabies ${ }^{(16)}$.

Menstrual Sicknessone of the most important causes of absenteeism among adolescent girls as it disturbs their academic performance and also has a negative impact on their $\mathrm{QOL}^{(14,32)}$.The International Association for the Study of 
Pain has reported that at every menstruation, approximately $10 \%-15 \%$ of adolescent girls are unable to work for 1 to 3 days ${ }^{(33)}$.The menstrual pain negatively affects the everyday physical activities $(22.5 \%)$, concentration in classes' hours $(27.9 \%)$, school attendance (6.9\%), and academic achievement $(31.1 \%)$ of the adolescents $^{(34)}$. Audio drama is primarily created with blind persons. For blind adolescent girls, audio drama replaces absent visual material with a sound commentary ${ }^{(35,36)}$.

In Egypt at the same setting of present study (Al Noor institute for visually impaired students at Shebein El-kom City in Menoufia Governorate, Egypt) concluded that nearly all of the studied participants have moderate amount of menstrual blood and nearly half of them $(57.1 \%)$ have pain during menstruation ${ }^{(37)}$.Therefore, this study aimed to examine the effect of audio- drama nursing intervention utilizingpeer education on menstrual hygiene and sickness management among blind adolescent.

\section{Aim of the study:}

The current study aimed to examine the effect of audio- drama nursing intervention utilizing peer education on menstrual hygiene and sickness management among blind adolescents.
This aim could be achieved through the following objectives:

1. Assess knowledge and practice of blind adolescent girls regarding menstrual hygiene and sickness management before and after implementing audio- drama nursing intervention utilizing peer education.

2. To implement audio- drama nursing intervention utilizing peer education upon menstrual hygiene and sickness management.

3. To assess the level of satisfaction among blind adolescent girls on audio drama nursing intervention utilizing peer education on menstrual hygiene and sickness management.

\section{Research hypothesis:}

1. Blind adolescent girls' knowledge about menstrual hygiene and sickness management would be improved after receiving of audio- drama nursing intervention utilizing peer education.

2. Blind adolescent girls' practice about menstrual hygiene and sickness management would be improved after receiving of audio- drama nursing intervention utilizing peer education.

3. Blind adolescent girls' satisfaction about audio- drama nursing intervention utilizing peer education would be improved after receiving the 
intervention.

\section{Methods:}

\section{Research Design:}

Quasi- experimental design (pre and posttest) was used to accomplish the current study.

\section{Setting:}

The current study was conducted at $\mathrm{Al}$ Noor institute for visually impaired students at Shebein El-kom City in Menoufia Governorate, Egypt. This setting is broad governmental school.

\section{Subject:}

A convenient sample of 40 blind adolescent girls was recruited in this study. Subject allocation

The researchers choose five peer students group from third-level blind adolescent girls' students to be a volunteer in educating the other adolescent girls and excluded from the study results. The reminder of the study sample (40) was divided into five. Each group consisted of 8 blind adolescent girls. The study sample was chosen according to the following criteria:

\section{Inclusion criteria:}

Blind adolescent girls:-

1. Aged 12-18 years and have menarche.

2. Who are willing to participate in the study and follow the instruction.

3. Who have no verbal or hearing response problems.

4. Who are available during the study period.

\section{Exclusion criteria}

Blind adolescent girls:-

1. Aged less than 12 years old

2. Who have verbal or hearing response problems.

3. Who are not willing to participate in this study.

\section{Subject size:}

A total of (40) blind adolescents girls were selected according to the following

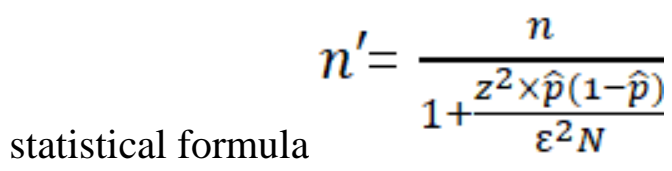

Wherez is the $\mathrm{z}$ score $\varepsilon$ is the margin of errorN is population size $\hat{p}$ is the population proportion

\section{Tools of data collection:}

Structured interviewing questionnaire was used to collect data. It contained four instruments as the following: designed

Instrument I: A structured Interviewing questionnaire was designed by the researchers and included two parts

Part I: Demographic data such as; age, standard of education, area of residence, care giver's education.

Part II: Menstrual data. It included (8 questions) about age at menarche, 
menstrual cycle duration, days of menstrual flow, pain experience and other discomfort during menstruation, types of discomfort weather physical as lack of concentration, backache/ joint and muscle pain/body ache, pain in the pelvic region....etc. or psychological as anxiety/ tension, outbursts of anger/ bad temper/frustration, feeling sad/ cranky/ depressed, .......etc.

Instrument II.An interviewing questionnaire on knowledge about menstruation; that was adopted from (Fricke et al., 2018) ${ }^{(38)}$ to assess level of blind adolescent girls' knowledge about menstruation.It included (18 closed questions) that were classified into two parts:

Part I: Knowledge about menstrual hygiene questionnaire.

It included 11 closed questions as knowledge about menstruation, source of information, purpose of menstrual hygiene, the best approach used to absorb the menstrual blood,time needed to change sanitary pad or cloth, method of disposing pads,place to dry out cloths used in menstruation, material used for cleaning of external genitalia,method used to clean perineal area,the best method of hand hygiene during menstruation used, and bath pattern during menstruation.
Part II: Knowledge about management of menstrual sickness questionnaire. It included 7 closed questions as symptoms that women commonly experience during the menstrual cycle, the method used to relieve a menstruation pain, therapy used for reduce menstrual pain,the method helps to relieve breast pain in during menstruation, definition of oligomenorrhoea, definition of polymenorhhoea and needs of girls during menstruation. Each correct answer was taken a score of 1 and in correct answer was taken a score of zero. The total knowledge score was 18 .it was calculated as the following:-

\section{Knowledge scoring system:}

\begin{tabular}{|l|l|l|}
\hline Item & Score & percentage \\
\hline Poorknowledge & $<9$ & $<50 \%$ \\
\hline fair knowledge & $9-14$ & $50 \%-75 \%$ \\
\hline Goodknowledge & $>14$ & $>75 \%$ \\
\hline
\end{tabular}

checklist on practice of menstrual hygiene and management of menstrual sickness. That was adopted from(Bijlani and Pardeshi, 2016) [39] to determine menstrual hygiene and management practice among blind adolescent girls. It included 3 closed and broad (yes/ no) questions. It included 15 sub questions about methods used for hygienic practice and management of menstrual sickness, 
how to deal with cloth used as an absorbent, and how to use sanitary pad as an absorbent. Each broad question contains sub questions. Each item of practice score will be given as follows: 1 score for yes answer, and zero score for no answer. The total practices score was15.it was calculated and practices scores will be considered as the following:-

\section{Practice scoring system:-}

\begin{tabular}{|l|l|l|}
\hline Item & Score & $\%$ \\
\hline PoorPractice & $<8$ & $<50 \%$ \\
\hline AveragePractice & $8-11$ & $50 \%-75 \%$ \\
\hline GoodPractice & $>11$ & $>75 \%$ \\
\hline \multicolumn{2}{|l|}{ Interviewing }
\end{tabular}

questionnaire on satisfaction level. That was adopted from(Bijlani and Pardeshi, $2016)^{(39)}$. It was used to assess satisfaction level on audio drama nursing intervention using peer education among blind adolescent girls. It included five items with 3 options, highly satisfied $=3$, satisfied $=$ 2 , and dissatisfied $=1$. Hence the obtainable score is $5-15$ and the score was converted into percentage and interpreted as follows.

\section{Level of satisfaction scoring system:-}

\begin{tabular}{|l|l|l|}
\hline Item & Score & $\%$ \\
\hline Dissatisfied & $<8$ & $<50 \%$ \\
\hline Satisfied & $8-11$ & $50 \%-75 \%$ \\
\hline Highly satisfied & $>11$ & $>75 \%$ \\
\hline
\end{tabular}

\section{Methods:}

\section{Review of literature:}

Revision to the literatures related to the title of study was done using articles, journals, textbooks, and network about the studies were done on audio-drama hygienic practice of menstruation and peer education among blind adolescent girls.

\section{Administrative and ethical aspects:}

Official steps were done to obtain permission to conduct the current study at Shebein El-kom Al Noor institute, written approval letter was taken from the responsible authorities ( Faculty of Nursing Dean at Menoufia University to the director of the Al Noor institute ) after explaining the purpose of the current study and programmed schedule for completion of the study procedures. All data about objectives, importance of the study and procedures of the current study were explained to all blind girls, the subjects were informed that they have the right to participate or withdrawn from the study at any time. The blind girls reassured that the information taken would be confidential and the researchers used it only to achieve the purpose of the study.

\section{Validity of the tools:}

The instruments I, II \& III used in the current study was reviewed and tested for the content and face validity by a group of 
five experts (from community health nursing, obstetric health nursing and pediatric health nursing of the tool). The tool was considered valuable, supportive and valid from the experts' perspective. Suggestions for any modification were incorporated in to the instruments.

\section{Reliability of the tools:}

Thereliability of the questionnaire was identified using test re- test method and interrater technique. Karl Pearson's 'r' was computed for determining the reliability instrument I, II and the correlation in both structuredquestionnaire was high $(\mathrm{r}=0.94)$. The reliability for instrument III (practice checklist)

was $(r=0.92)$ usinginterratertechniqueandrati ngscale while the reliability for blind adolescent girls' satisfaction was $(\mathrm{r}=0.92)$ using test re-test method

\section{Pilot study:}

A pilot study was carried out before beginning the actual data collection. The tool was tested on a sample of four blind adolescent girls who were not incorporated in the main study sample. Based on pilot study results, the needed time to complete the questionnaire was considered and the necessary modification and clarification of some questions were done.

\section{Data collection \& Procedure:}

Data collection for the present study began from the first of February 2020 till the first of March 2020.

The data was collected through the following phases:

\section{1- The assessment phase:}

In this phase, the researchers started by introducing themselves to the blind adolescent girls, gave them a concise idea, aims, and predictable outcomes of the study. Then, oral consent was obtained from the girls. The researchers were interviewing the blind adolescent girls and began to explain questionnaire components and the research plan. After explanation, the researchers began to fill pretest by reading the questions to each girl and then their responses were marked on the questionnaires. Each blind adolescent girl was assessed by identifying her socio demographic data, menstrual history, level of knowledge and practice about menstrual hygiene and sickness management. The filling of pretest took from 20 to 30 minutes. The researchers told the blind adolescent girls that there would be some posttest after explaining educational session and follow up assessment after 1 month. 
2- The implementation phase: This phase passes through four steps

First: The researchers interviewed with the chosen five students peer group and began to train them to be able to educate and express peer education. The researchers provided training education for peer educators through conversation between researchers about knowledge and practice of safety method used in menstrual hygiene and sickness management. Then the group began to redemonstrate conversation until they were prefect in expressing education. This training took 3sessions/a week. Each session took about 45 minutes. First session for knowledge about menstruation Second session about practice and third session for revision to confirm the ability to educate and express peer education

Second: For audio- drama using peer education accomplishment, the researchers began to record the audio drama. It is a recorded conversation between the five students peer group about knowledge and practice of safety method used in menstrual hygiene and sickness management. Audio drama is a dramatized, purely audio performance is played on conversation, music and sound effects with no visual aids to help blind adolescent girls to understand all knowledge about menstruation. For blind adolescent girls, audio drama replaces absent visual material with a sound commentary .Audio drama is more effective and efficient way to promote health and wellbeing by using drama to develop knowledge and practices of blind adolescent girls through their aids.

Third: The researchers began to sit the blind adolescent girls comfortably in the class, setting the laptop and speakers to be connected correctly, the blind adolescent girls are divided into five groups, each group included 8 girls, each peer educator with the help of researchers educated one group about knowledge and practice of safety method used in menstrual hygiene and sickness management, explained to them about audio drama and instructed them to maintain calm to hear clearly, after education completed, the audio drama was played for duration of 30 minutes. After the audio dram ended, the researchers asked the students if they need to repeat conversation, discuss with the girls, answer all questions and make them clear in all aspects of the audio drama.

\section{3- The evaluation phase}

In this phase, the researchers filled posttest to assess level of knowledge and practice about menstrual hygiene and sickness management immediately after explaining 
educational session by reading the questions to each girl and then their responses were marked on the questionnaires.It took about 30 minutes .Follow up assessment after 1 month, the researches followed the studied blind adolescent girls for re-assessment and reporting the effect of audio dram nursing intervention utilizing peer education on menstrual hygiene and sickness management and answering any concern from the girls to reassess minor sickness of menstruation ,level of knowledge and practice about menstrual hygiene and sickness management and assessment of satisfaction level on audio dram nursing intervention among blind adolescent girls. It took about 30-45 minutes.

\section{Limitations and Bias of the Study}

The limitation is the small sample size; so, the results may not be generalized beyond the study.

\section{Statistical analysis:}

Data was coded and transformed into specially designed form to be suitable for computer entry process. Data was entered and analyzed by using Statistical Package for Social Science (SPSS) version 22. Graphics were done using Excel program. Quantitative data were expressed as mean and standard deviation (X \pm SD). Qualitative data were expressed as number and percentage (No \& \%). It was analyzed by using chi-square test $\left(\mathrm{X}^{2}\right)$ for $2 \mathrm{X} 2$ table, ANOVA test used to analyze the differences among group means.

\section{P-value at 0.05 was used to determine} significance regarding:

- P-value > 0.05 to be no statistically insignificant.

- P-value $\leq 0.05$ to be statistically significant.

- P-value $\leq 0.001$ to be high statistically significant.

\section{Results:}

Table (1): Represents demographic characteristics of the studied sample. It was obvious from this table that $55 \%$ were between age 16- 18 years and the mean age group among studied sample was $15.2 \pm$ 1.91. Regarding education, more than half of studied blind adolescent girls were receiving secondary education. Regarding residence, $55 \%$ of the studied girls were from rural areas. RegardingCaregiver education, $62.5 \%$ of them had secondary education.

Table (2):Illustrates percent distribution of studied sample according to menstrual history.It illustrates that $75 \%$ of the studied girls had menstrual period before reaching 14 years and the mean age group at menarche among studied sample was 13.8 \pm 1.26 , more than half of them $(55 \%)$ had 
3-5 days of menstruation and the mean duration of menstruation among them was $5.7 \pm$ 1.6. Regardingmenstrual interval, $50 \%$ of the studied sample had 28- 35 days of menstrual interval. Regarding amount of blood, the majority of the studied girls $(82.5 \%)$ had moderate amount of menstrual bloodand all of them had minor discomfort during menstrual period.

Figure (1): Clarifies source of information regarding menstruation among studied blind adolescent girls. It illustrates that $77 \%$ of Studied sample had information regarding menstruation from their mothers, $15 \%$ of them had information from teachers , and $8 \%$ from mass media.

Table (3): Represents menstrual sickness among blind adolescent girls on preand on follow up. Regarding physical symptoms, it illustrates that all of blind girls (100\%) had backache/ joint and muscle pain/body ache, fatigue/ tiredness and pain in the pelvic region on pre education while $30.0 \%$ of them didn't have backache/ joint and muscle pain/body ache, $50.0 \%$ of them didn't have fatigue/ tiredness and $32.5 \%$ of them didn't have pain in the pelvic region on post education. Regarding psychological symptoms, the majority of them had anxiety / tension and outbursts of anger/ bad temper/frustration $(85.0 \%$ and $80.0 \%$ respectively) on pre education while only $32.5 \%$ of them had anxiety / tension and $37.5 \%$ of them had outbursts of anger/ bad temper/frustration on post education. Also, three quarter of them $(75.0 \%)$ had feeling sad/ cranky/ depressed and changes in sleep cycle on pre education while $75.0 \%$ of them didn't have feeling sad/ cranky/ depressed and $50.0 \%$ of them didn't have changes in sleep cycle on follow up. For this reason, there were statistical and highly statistical significant improvement among blind adolescent girls after one month of enrollments and after the following menstruation in some of physical and psychological symptoms of menstruation in post interventions than in pre education $(\mathrm{P}<0.05)$.

Table (4): shows distribution of level of knowledge on menstrual hygiene and menstrual sickness management among studied sample on pre, post and follow-up tests. It is obvious that majority of blind adolescent girls had higher level of knowledge about menstrual hygiene and menstrual sickness management on post and follow up tests than on pretest. For this reason, there were highly statistical significant differences among blind adolescent girls' knowledge in post intervention than in pre intervention $(\mathrm{P}<0.001)$. 
Table (5): Illustrates frequency and percentage distribution of level of reported practice on menstrual hygiene and sickness management of among blind adolescent girls on pre, post and follow-up tests. It illustrates that there was an improvement in the level of practice among blind adolescent girls regarding menstrual hygiene and sickness management among studied sample on post and follow up tests than on pretest. For this reason, there were highly statistical significant differences among blind adolescent girls ' practice in post intervention than in pre intervention $(\mathrm{P}<0.05)$.

Table (6): Represents mean and standard deviation of knowledge and practice on pre, post and follow-up tests onmenstrual hygiene and menstrual sickness management of among blind adolescent girls. Regarding students' knowledge, mean scores on pre intervention were 8.62 \pm 1.35 compared to $20.50 \pm 1.38$ and $18.32 \pm 1.53$ on post and follow- up tests respectively. While, mean scores of students' practice on pre intervention were $5.87 \pm 1.18$ compared to $13.75 \pm 1.36$ and $12.13 \pm 2.0$ on post and follow- up tests respectively. Therefore, there were highly statistical significant improvement between students' knowledge and practice in post intervention than in pre intervention $(\mathrm{P}<0.05)$.

Figure (2): clarifies frequency and percentage distribution of level of satisfaction regarding audio drama on menstrual hygiene and management of minor ailments of menstruation among blind adolescent girls. Three quarters of them (75\%) were highly satisfied with audio drama. 
Table (1): Demographic characteristics of the studied blind adolescent girls $(n=40)$

\begin{tabular}{|c|c|c|}
\hline $\begin{array}{l}\text { Demographic characteristics of } \\
\text { blind adolescent girls }\end{array}$ & $\begin{array}{l}\text { No } \\
(n=40)\end{array}$ & $\%$ \\
\hline Age & & \\
\hline $12-15$ years & 18 & 45.0 \\
\hline 16- 18 years & 22 & 55.0 \\
\hline \multicolumn{3}{|c|}{ Mean \pm SD } \\
\hline \multicolumn{3}{|c|}{$15.2 \pm 1.91$} \\
\hline Education & & \\
\hline Preparatory & 17 & 42.5 \\
\hline Secondary & 23 & 57.5 \\
\hline Residence & & \\
\hline Rural & 22 & 55.0 \\
\hline Urban & 18 & 45.0 \\
\hline Caregiver education & & \\
\hline Illiterate & 6 & 15.0 \\
\hline Read and write & 7 & 17.5 \\
\hline Secondary education & 25 & 62.5 \\
\hline University education & 2 & 5.0 \\
\hline
\end{tabular}


Table (2): Percent distribution of studied sample according to menstrual history

\begin{tabular}{|c|c|c|}
\hline Items & $\begin{array}{l}\text { No } \\
(n=40)\end{array}$ & $\%$ \\
\hline $\begin{array}{l}\text { Age at menarche in years } \\
\leq 14 \text { years } \\
15-16 \text { years }\end{array}$ & $\begin{array}{l}30 \\
10\end{array}$ & $\begin{array}{l}75.0 \\
25.0\end{array}$ \\
\hline \multicolumn{2}{|c|}{ Mean \pm SD } & \\
\hline $\begin{array}{l}\text { Duration of menstruation } \\
3-5 \text { days } \\
>5 \text { days }\end{array}$ & $\begin{array}{l}22 \\
18\end{array}$ & $\begin{array}{l}55.0 \\
45.0\end{array}$ \\
\hline \multicolumn{3}{|c|}{$\begin{array}{c}\text { Mean } \pm \text { SD } \\
5.7 \pm 1.60\end{array}$} \\
\hline $\begin{array}{l}\text { Menstruation interval } \\
\leq 28 \text { day } \\
28-35 \text { day } \\
>35 \text { days }\end{array}$ & $\begin{array}{l}16 \\
20 \\
4\end{array}$ & $\begin{array}{l}40.0 \\
50.0 \\
10\end{array}$ \\
\hline $\begin{array}{l}\text { Amount of menstrual blood } \\
\text { Moderate } \\
\text { Severe }\end{array}$ & $\begin{array}{l}33 \\
7\end{array}$ & $\begin{array}{l}82.5 \\
17.5\end{array}$ \\
\hline $\begin{array}{l}\text { Dysmenorrhea } \\
\text { No } \\
\text { Yes }\end{array}$ & $\begin{array}{l}16 \\
24\end{array}$ & $\begin{array}{l}40.0 \\
60.0\end{array}$ \\
\hline $\begin{array}{l}\text { Presence of minor discomfort } \\
\text { Yes }\end{array}$ & 40 & 100.0 \\
\hline
\end{tabular}




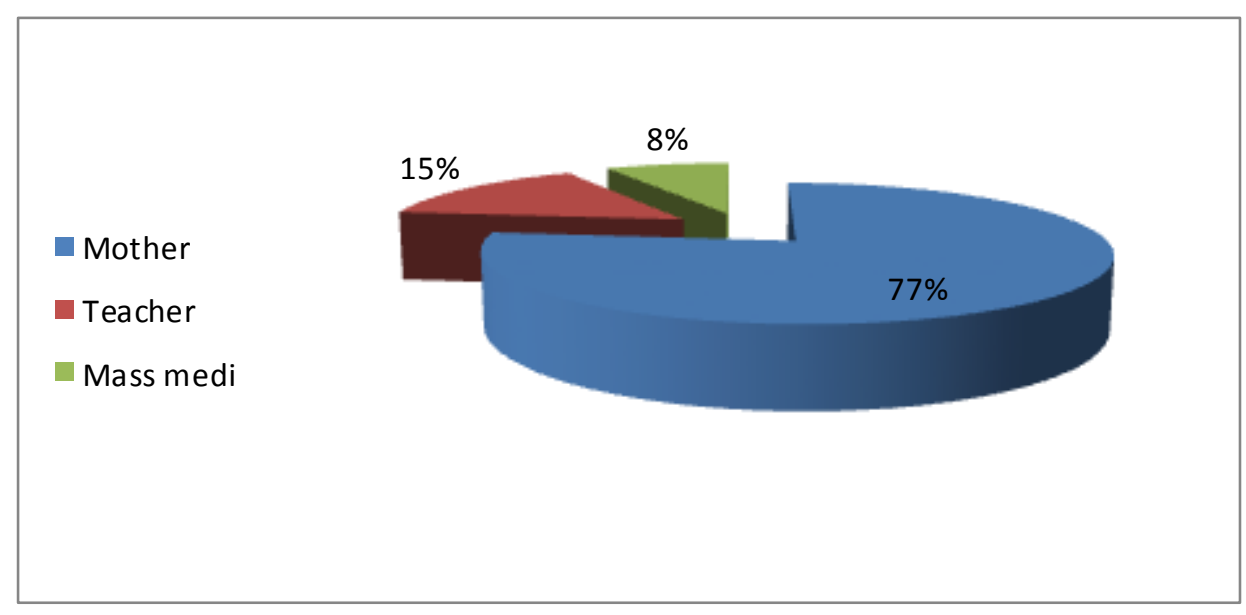

Figure (1): Source of information regarding menstruation among blind adolescent girls

Table (3): Distribution of minor sickness of menstruation among blind adolescent girls on pre and on follow up

\begin{tabular}{|c|c|c|c|c|c|c|c|c|c|}
\hline \multirow[t]{3}{*}{ Minor Ailments } & \multicolumn{4}{|c|}{ Pre education } & \multicolumn{4}{|c|}{$\begin{array}{l}\text { Follow up } \\
\text { (after one month) }\end{array}$} & \multirow[t]{3}{*}{$\begin{array}{l}\mathbf{P} \\
\text { value }\end{array}$} \\
\hline & \multicolumn{2}{|l|}{ Yes } & \multicolumn{2}{|l|}{ No } & \multicolumn{2}{|l|}{ Yes } & \multicolumn{2}{|l|}{ No } & \\
\hline & No & $\%$ & No & $\%$ & No & $\%$ & No & $\%$ & \\
\hline \multicolumn{10}{|l|}{ Physical symptoms } \\
\hline Lack of concentration & 5 & $12.5 \%$ & 35 & $87.5 \%$ & 3 & $7.5 \%$ & 37 & $92.5 \%$ & .459 \\
\hline $\begin{array}{l}\text { Abdominal discomfort/ } \\
\text { GIT symptom }\end{array}$ & 30 & $75.0 \%$ & 10 & $25.0 \%$ & 27 & $67.5 \%$ & 13 & $32.5 \%$ & .459 \\
\hline $\begin{array}{l}\text { Backache/ Joint and } \\
\text { muscle pain/Body ach }\end{array}$ & 40 & $100.0 \%$ & 0 & $0.0 \%$ & 28 & $70.0 \%$ & 12 & $30.0 \%$ & $.000 * *$ \\
\hline $\begin{array}{lr}\text { Oedema/ } & \text { Swelling/ } \\
\text { Puffiness/ } & \text { Water } \\
\text { retention } & \end{array}$ & 4 & $10.0 \%$ & 36 & $90.0 \%$ & 4 & $10.0 \%$ & 36 & $90.0 \%$ & 1.000 \\
\hline $\begin{array}{l}\text { Pain/ Tenderness/ } \\
\text { Enlargement/Swelling } \\
\text { of breasts }\end{array}$ & 29 & $72.5 \%$ & 11 & $27.5 \%$ & 23 & $57.5 \%$ & 17 & $42.5 \%$ & .160 \\
\hline Fatigue/ Tiredness & 40 & $100.0 \%$ & 0 & $0.0 \%$ & 20 & $50.0 \%$ & 20 & $50.0 \%$ & $.000^{* *}$ \\
\hline $\begin{array}{l}\text { Pain in the pelvic } \\
\text { region }\end{array}$ & 40 & $100.0 \%$ & 0 & $0.0 \%$ & 27 & $67.5 \%$ & 13 & $32.5 \%$ & $.000 * *$ \\
\hline $\begin{array}{l}\text { Feeling bloated/ Weight } \\
\text { gain }\end{array}$ & 34 & $85.0 \%$ & 6 & $15.0 \%$ & 32 & $80.0 \%$ & 8 & $20.0 \%$ & .556 \\
\hline
\end{tabular}




\begin{tabular}{|l|c|c|c|c|c|c|c|c|c|c|c|}
\hline $\begin{array}{l}\text { Skin changes (Rashes/ } \\
\text { Acne) }\end{array}$ & 35 & $87.5 \%$ & 5 & $12.5 \%$ & 35 & $87.5 \%$ & 5 & $12.5 \%$ & 1.000 \\
\hline Psychological symptoms & 34 & $85.0 \%$ & 6 & $15.0 \%$ & 13 & $32.5 \%$ & 27 & $67.5 \%$ & $.000^{* *}$ \\
\hline Anxiety / Tension & 32 & $80.0 \%$ & 8 & $20.0 \%$ & 15 & $37.5 \%$ & 25 & $62.5 \%$ & $.000^{* *}$ \\
\hline $\begin{array}{l}\text { Outbursts of anger/ Bad } \\
\text { temper/Frustration }\end{array}$ & 30 & $75.0 \%$ & 10 & $25.0 \%$ & 10 & $25.0 \%$ & 30 & $75.0 \%$ & $.000^{* *}$ \\
\hline $\begin{array}{l}\text { Feeling sad/ Cranky/ } \\
\text { Depressed }\end{array}$ & 30 & $75.0 \%$ & 10 & $25.0 \%$ & 20 & $50.0 \%$ & 20 & $50.0 \%$ & $.021 *$ \\
\hline \begin{tabular}{l} 
Changes in sleep cycle \\
\hline
\end{tabular}
\end{tabular}

Table (4): Distribution of level of knowledge on menstrual hygiene and sickness management of among blind adolescentgirls on pre, post and follow-up tests

\begin{tabular}{|l|l|l|l|l|l|l|l|l|}
\hline & \multicolumn{9}{|l|}{ Total score of students' knowledge } & $\chi^{2} 1$ & $\chi^{2} 2$ \\
\hline Items & Pre test & \multicolumn{2}{l|}{ Post test } & \multicolumn{2}{l|}{ Follow-up } & P1- & P2- \\
\hline & No. & $\%$ & No. & $\%$ & No. & $\%$ & & \\
\hline Poorknowledge & 30 & $75.0 \%$ & 0 & $0.0 \%$ & 2 & $5.0 \%$ & & \\
fair knowledge & 10 & $25.0 \%$ & 5 & $12.5 \%$ & 10 & $25.0 \%$ & 66.67 & 60.14 \\
Goodknowledge & 0 & $0.0 \%$ & 35 & $87.5 \%$ & 28 & $70.0 \%$ & $.000 * *$ &. $.000 * *$ \\
\hline
\end{tabular}

Table (5): Distribution of level of reported practice on menstrual hygiene and menstrual sickness management of among blind adolescentgirls on pre, post and follow-up tests.

\begin{tabular}{|l|l|l|l|l|l|l|l|l|}
\hline & \multicolumn{6}{|l|}{ Total score of students' reported practice } & $\chi^{2} 1$ & $\chi^{2} 2$ \\
\hline Items & \multicolumn{2}{|l|}{ Pre test } & \multicolumn{2}{l|}{ Post test } & \multicolumn{2}{l|}{ Follow-up } & & \\
\hline & No. & $\%$ & No. & $\%$ & No. & $\%$ & P1-value & P2-value \\
\hline Poor practice & 32 & $80.0 \%$ & 2 & $5.0 \%$ & 4 & $10.0 \%$ & & \\
\hline Average practice & 8 & $20.0 \%$ & 16 & $40.0 \%$ & 18 & $45.0 \%$ & 51.13 & 49.18 \\
\hline Good practice & 0 & $0.0 \%$ & 22 & $55.0 \%$ & 18 & $45.0 \%$ & $.000 * *$ &. $.000 * *$ \\
\hline
\end{tabular}


Table (6): Mean and standard deviation of knowledge and practice on pre, post and follow-up tests on menstrual hygiene and sickness management of among blind adolescentgirls

\begin{tabular}{|l|l|l|c|c|c|}
\hline Variables & $\begin{array}{l}\text { Pre test } \\
(\text { Mean } \\
\text { SD) }\end{array}$ & $\begin{array}{l}\text { Post test } \\
(\text { Mean } \pm \text { SD) }\end{array}$ & $\begin{array}{l}\text { Follow-up } \\
(\text { Mean } \pm \text { SD) }\end{array}$ & Anova test & P-value \\
\hline $\begin{array}{l}\text { Students' } \\
\text { knowledge }\end{array}$ & $8.62 \pm 1.35$ & $20.50 \pm 1.38$ & $18.32 \pm 1.53$ & $-4.065-$ & .000 \\
\hline $\begin{array}{l}\text { Students' } \\
\text { practice }\end{array}$ & $5.87 \pm 1.18$ & $13.75 \pm 1.36$ & $12.13 \pm 2.0$ & $-7.476-$ & .000 \\
\hline
\end{tabular}

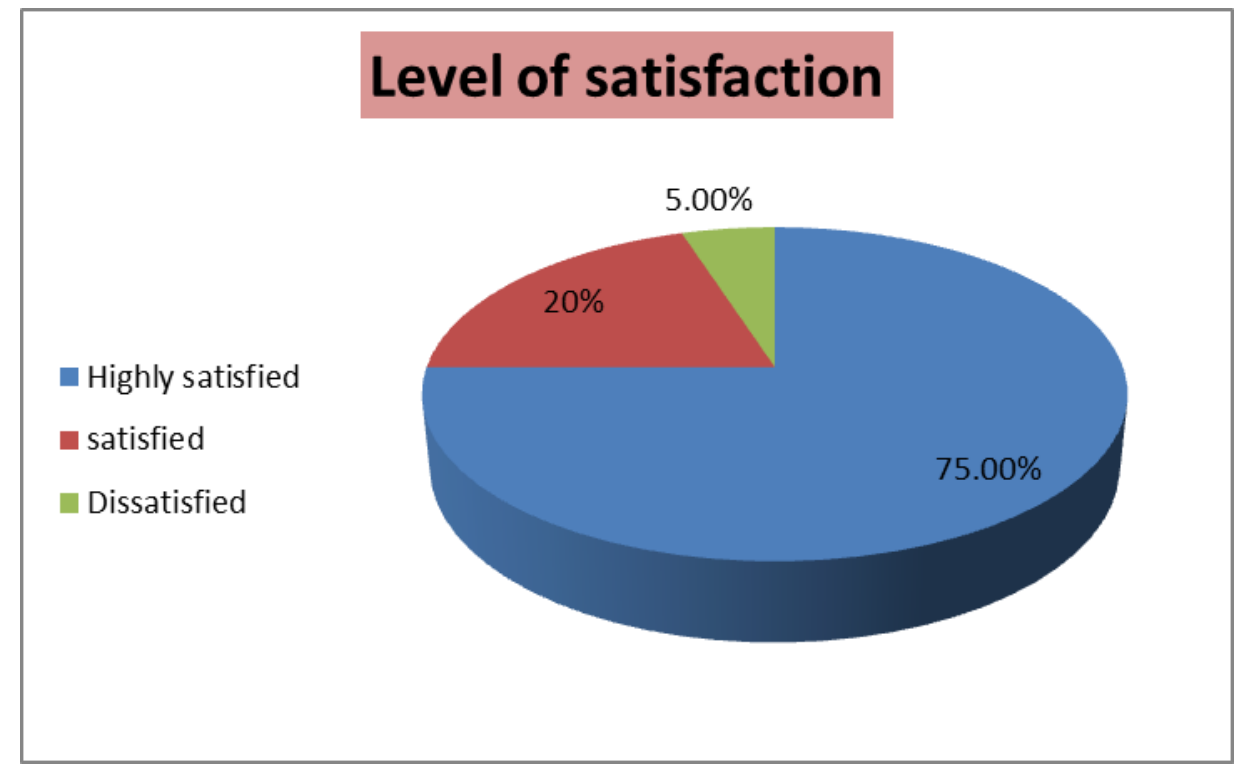

Figure (2): Distributionoflevelofsatisfactionregardingaudiodrama on menstrual hygiene and management of sickness management of among blind adolescentgirls 


\section{Discussion:}

Menstruation is the main indicator of cyclic physiologic uterine bleeding due to cracking of the endometrium. Adolescent girls are considered one of a vulnerable group, particularly blind adolescent girls. Good health hygiene related practices of adolescent girls during menstruation are important to prevent infection of the genital area. So, it is important for the nurse to use audio drama program with peer education to improve knowledge and practice in the overall aspects of the menstrual hygienic practices among blind adolescent girls ${ }^{(9,16,38)}$.

Regarding demographic characteristics of studied blind adolescent girls, the current study displayed that the half of the sample were between age 16-18 years, at the classes V-VIII, and more than half of them were residing in rural areas. Also, it presented that more than half of girls, caregivers had secondary education. This result was similar to previous study ${ }^{(39)}$,who stated that that half of the blind adolescent girls were between 16-19 years old and about half of them at the classes VVIII. These findings are not supported by a study ${ }^{(40)}$.They reported that $60 \%$ the visually challenged girls were at the age of 14 years old, half of them were studying at 9th level and the entire study sample were living in urban area and caregivers had secondary education.

Regarding percent distribution of studied sample according to menstrual history, the current study revealed that, three quarters of the blind adolescent girls had menstruation before reaching 14 years old, more than half of them had 3-5 days as the number menstrual days and 28-30 days as menstrual interval. In addition, the majority of the blind adolescent girls had moderate amount of menstrual blood and all of them had minor discomfort during menstrual period. The results were similar to previous study ${ }^{(41)}$. They reported that age of menarche of the visually challenges adolescent girls was between 11-14 years, their menstruation lasts from 3 to 5 days, all of them had minor alignments during menstruation but two third of them had severe bleeding and irregular menstruation and their interval between menstruations were above 35 days.

Also these results are supported by a previous study ${ }^{(42)}$. That showed that half of the students of blind adolescent girls had menstruationattheageof12-14years, about more than half of them had duration of menstrual cycle above 30 days, students had menstrual flow about 5-7days, and all of the sample had minor complains during 
menstruation. This discrimination in menstrual intervals and bleeding may be due to personal differences or difference in hormonal changes among blind adolescent girls.

In relation to source of information regarding menstruation among studied blind adolescent girls, the present study showed that slightly more than three quarters of studied blind adolescent girls had information regarding menstruation from their mothers, less than on fifth of girls had information from teacher and peers, and minority of them has knowledge from mass media. Also the present study results support previous findings ${ }^{(13)}$.They reported that among one hundred of adolescent girls, the majority of them $(84 \%)$ had their source of information from mothers and only $16 \%$ girls had information about menarche from teachers and their friendsThese findings is also supported by the study that was done by (34), they reported that the majority of the blind adolescent girls' their mothers were the information source concerning menstruation whereas, $15.1 \%$ were from their teachers and $5.7 \%$ were from mass media.

In addition, these findings are not supported by the study ${ }^{(43)}$. They reported that all blind adolescent girls had a previous knowledge about menstruation and all of them had their source of information from their parents. This disagreement may be due to that difference in culture, tradition and education in rural areas than urban areas. Also, it may be due to poor attention from the teachers to satisfy the educational needs of adolescent girls regarding menstruation.

Concerning distribution of minor sickness of menstruation among blind girls on pre and post education after one month of audio drama intervention and good menstrual hygienic practices and after finishing the next menstruation, slightly less than one third of the studied girls didn't have backache/ joint and muscle pain/body ache, half of them didn't have fatigue/ tiredness and one third of them didn't have pain in the pelvic region, slightly more than two thirds didn't had anxiety / tension, slightly less than two thirds didn't had outbursts of anger/ bad temper/frustration, half of them didn't have changes in sleep cycle. Also, there were statistical significant improvement among blind adolescent in physical and psychological minor sickness of menstruation in post education than in pre education $(\mathrm{P}<0.05)$. Also the present study results support previous findings ${ }^{(5)}$.They reported that the majority of blind 
adolescent girls' reported an improvement of menstrual minor alignments after application of measures regarding menstrual minor alignments management receiving education of structured audio educational sessions regarding menstruation. Also the present study results support previous findings ${ }^{(34)}$. They reported that after three months of intervention, blind adolescent girls reported an improvement of minor symptoms of menstruation especially back pain, pain of pelvic region and improving in sleeping. This agreement may be due to audio drama intervention is effective in improving menstrual sickness management among blind adolescent girls.

In relation to pre, post and follow-up tests of level of knowledge on menstrual hygiene and menstrual sickness management among studied sample. The present study shown that that majority of blind adolescent girls had higher levels of knowledge on post and follow up tests than on pre intervention. This results were similar to previous study ${ }^{(5)}$. They reported that after audio drama intervention, the visually challenged girls had improvement in level of knowledge in post intervention than in pre intervention. Also these findings are supported by the study that was done by (Hennegan, 2016). Who stated that the most of visually impaired girls had incorrect knowledge in pre intervention of audio drama session while the majority of studied sample had correct knowledge in post and follow up tests after one month of enrollment ${ }^{(15)}$. This agreement may be due to that importance of using audio drama program to improve menstruation hygiene and practice among blind adolescent girls.

Concerning of pre, post and follow-up tests of level of practice on menstrual hygiene and menstrual sickness management among studied sample, the current study shown that there was an improvement in the level of practice among blind adolescent girls on post and follow up tests than on pre intervention.. This result was similar to previous studies ${ }^{(31)}$.They reported that most of blind adolescent girls had poor practices about menstrual hygiene and management of minor complaints before the audio-drama education regarding menstruation compared to post intervention and there was a highly statistical significant difference at $\mathrm{P} \leq 0.001$.

In addition, the present study results support previous findings ${ }^{(15)}$.They showed that there were improvements in the visually challenged girls, practices regarding personal hygiene and 
menstruation practice after one month of implementation of audio drama program using peer education than before implementation with highly statistical significant differences. This agreement in findings may be attributed to the effect of audio drama nursing intervention using peer education in changing practice of blind adolescent girls regarding menstrual hygiene and sickness management.

Regarding mean scores of pre, post and follow-up tests of knowledge and practice on menstrual hygiene and sickness management among studied sample, the current study stated that there were improvement in mean score in post intervention and follow up tests of knowledge and practice in post intervention and follow up tests than in pre intervention. In addition it presented that there were highly statistical significant differences between the blind adolescent girls' knowledge and practice. These findings are congruent with precious study ${ }^{(41)}$. they stated that there were obvious improvement in mean and standard deviation in knowledge among studied sample between pretest versus posttest I (5.31 $\pm 1.03,13.4 \pm 0.48$ respectively ) and

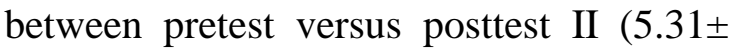
$1.03,13.13 \pm 2.36$ ). Also, there was improvement in mean and standard deviation of practice in posttest I and posttest II than in pre intervention. They reported that there was a highly statistically significant difference.

In relation to distribution of satisfaction level regarding using of audio drama with peer education on menstruation among the studied sample, the present study showed that three quarters of them had high satisfaction related to the use of audio drama intervention. These results are consistent with the previous study ${ }^{(42)}$.They described that the majority $(88.7 \%)$ of the visually challenged adolescent girls were had high satisfaction regarding the audio drama program including explanation of the menstrual educational sessions.

Also, these findings are supported by the study ${ }^{(43)}$ they reported that the majority $(80 \%)$ of the blind adolescent girls were satisfied regarding the researchers, and audio drama intervention on menstruation while $20 \%$ only had high satisfaction. This agreement may be due to that finding indicated that the intervention is harmless, competent and economic and easy to follow. Also, it gives a strong picture that blind adolescent girls can benefit through the using of audio drama method.

\section{Conclusion:}

In the light of the present study findings, it could be concluded that the audio drama 
nursing intervention using peer education was an effective mean in improving of the blind adolescent girls' knowledge and practices regarding menstrual Hygiene and sickness management. Also, there was highly statistical improvement in menstrual symptoms, total scores of knowledge and practice and level of satisfaction regarding intervention among studied blind adolescent girls in posttest and follow up test than pre intervention.

\section{Recommendations:}

Based on the study results, the following recommendations are proposed:

- Continuous health education programs should be applied to raise the awareness of blind adolescent girls regarding menstruation in different setting.

- Integrating the topic of menstruation, menstrual hygiene and menstrual sickness management into the course contents of the blind schools objectives.

- Further research is required to expand understanding of special needs of blind adolescent girls and girls with various disabilities regarding menstruation.

- A comparative study can be conducted between normal and blind adolescent girls.

\section{References:}

1-Steinberg L. Age of opportunity: Lessons from the new science of adolescence. Boston, MA: Houghton Mifflin Harcourt; 2014. Available from: https://www.amazon.com/Age-

Opportunity-Lessons-ScienceAdolescence/dp/0544570294.

2- Jha S. Effectiveness of planned audio teaching program on menstrual hygiene in terms of knowledge among visually challenged adolescent girls, in selected blind school. 2018; 6(10). Available from:http://dx.doi.org/10.18535/ijsre/v6 $\underline{\mathrm{i} 7.04}$

3- National Institute of Public Cooperation and Child Development. Improvement in Knowledge and Practices of Adolescent Girls Regarding Reproductive Health with Special Emphasis on Hygiene during Menstruation in FiveYears.2014 .

4-Shahhosseini Z, Simbar M, Ramezankhani A, Alavi Majd H, Moslemizadeh N. The challenges of female adolescents' health needs. Community Ment.Health J. 2013; 16(5). Available from https://pubmed.ncbi. nlm.nih.gov/23677558/

5- Parameaswari M. Menstrual hygiene practices among Teenage Girls in Chennai. India Adolescents Health. 
$2013 ; 18(1): 113-20$.

6- Prabhu S, Nagrale S, Shyam A, Sancheti P. Effect of Yogasanas on menstrual cramps in young adult females with primary Dysmenorhea. AInternational Journal of Physiotherapy and Research. 2019; 7(4): 3129-34. ISSN 2321-1822 DOI: Available from: https://dx.doi.org/10.16965/ijpr.2019.140.

7- Sewanyana D, Bitanihirwe B. Menstrual hygiene management among adolescent girls in Sub-Saharan Africa. Glob Health Promot. 2019; 26(1):1058. Epub 2017/05/10. Available from: https://doi.org/10.1177/

1757975917694597 PMID: 28485220.

8- Gilbert C, Foster A .Childhood blindness in the context of VISION 2020 - The Right to Sight WHO.2020. Available from:https://www.who.int/ blindness/causes/priority/en/index3.html.

9-Fricke $\mathrm{T}$, Tahhan $\mathrm{N}$, Resnikoff $\mathrm{S}$, Papas E, Burnett A, Suit MH, et al. Global prevalence of Presbyopia and Vision Impairment from Uncorrected Presbyopia. Systematic Review.Metaanalysis, and Modelling. Ophthalmology. 2018; 9(5) 60-9

10- World Health Organization.Blindness and vision impairment. 2020. Available from: https://www.who.int/news-room/ fact-sheets/detail/blindness-and-visual- impairment

11- Jeyanthi P. Effectiveness of audio drama on menstrual hygiene and management of minor ailments of menstruation upon knowledge and practice among visually challenged girls.2020.Available from: https://ijisrt. com/effectiveness-of-audio-drama-onmenstrual-hygiene-and-management-ofminor-ailments-of-menstruation-uponknowledge-and-practice-amongvisually-challenged-girls.

12-Kamath R, Ghosh D, Lena A, Chandrasekaran V. A Study on knowledge and practices regarding menstrual hygiene among rural and urban adolescent girls in Udupi Taluk, Manipal, India.Global Journal of Medicine and Public Health. 2013; 2(4) 13-Mishra S.K, Dasgupta D, Ray S. A study on the relationship of sociocultural characteristics: Menstrual hygiene practices and gynaecological problems - adolescent girls in Eastern India. Indian Journal of Adolescents Med Health. 2016; 27(1): 10-14.

14-Eijk A. Menstrual hygiene management among adolescent girls in India: A systematic review and MetaAnalysis. Control and Prevention BMJ. 2016; 10(1): 9-11. 
15-Hennegan G .Measuring the prevalence and impact of poor menstrual hygiene management: A quantitative survey of schoolgirls in rural Uganda.British Journal of Medicine. 2016; 6(1): 12-20

16- Bijlani M, Pardeshi G. Prevalence and coping mechanisms of premenstrual syndrome (PMS) using a questionnaire and calendar technique. Indian Journal of Basic and Applied Medical Research. 2016; 5(2): 150-58.

17- House S, Mahon T, Cavill S. Menstrual hygiene matters. A resource for improving menstrual hygiene around the world. 2012. Available from: https://washmatters.wateraid.org/sites/g/file s/jkxoof256/files/Menstrual\%20hygiene\%2 0matters\%20low\%20resolution.pdf

18-Ministry of Drinking Water and Sanitation.Menstrual hygiene management.National guidelines. Government of India. 2015. Available from: $\quad$ http://unicef.in/Uploads/ Publications/Resources/pub_doc107.pdf . Accessed on 10 March 2016

19-Water Aid. Menstrual hygiene in South Asia; 2010A neglected issue for WASH (water, sanitation and hygiene) programmes. Available from:https:// www.tandfonline.com/doi/abs/10.1080/1 3552071003600083

20- Helwa H, Mitaeb S, Al-Hamshri,
Sweileh W. Prevalence of dysmenorrhea and predictors of its pain intensity among Palestinian female university students. BMC Women's Health. 2018; 18(1) . Available from:https://www.hindawi.com/journals/ ogi/2019/5834159/

21- Chauhan G, Kodnani A. A study of prevalence and impact of dysmenorrhea and its associated symptoms among adolescent girls residing in slum areas of Vadodara city, Gujarat.International Journal of Medical Science and Public Health. 2016; 5(3): 510-15. Available from https://www.ijmsph.com/?mno= 205923

22- Gebeyehu M, Mekuria A, Tefera A, Andarge D, Debay Y, Bejiga G, et al. Prevalence, impact, and management practice of dysmenorrhea among University of Gondar Students, Northwestern Ethiopia: A crosssectional study. Hindawi International Journal of Reproductive Medicine. 2017;. Available from: https://doi.org/10.1155/2017/3208276.

23- Abdi F, Simbar M. The peer education approach in adolescentsNarrative: Review Article Iran J. Public Health. 2013; 42(11): 1200-06. Available from: PMCID: PMC4499060PMID: 26171331. 
Available from https://www.ncbi.nlm.nih. gov/pmc/articles/PMC4499060/

24- Lisa F. Kids know what they are doing: Peer-led sex education in New York City". History of Education Quarterly. 2019; 59 (4): 501-527. Doi:10.1017/heq.2019.41.

25- Ali H, Hussein S..The effect of peer education on adolescent students' knowledge and performance of breast self-examination2018. Available from: https://www.enj.eg.net/article.asp?issn=2 0906021; year=2018; volume $=15$;issue $=1$; spage $=30$; epage $=38$; aulast $=\mathrm{E}$

26-Yucel S, Orgun F, Tokem Y, Avdal U, Demir M . Determining the factors that affect breast cancer and self-breast examination beliefs of Turkish nurses in academia. Asian Pac J. Cancer Prev. 2014; 15(1):1275-80.

27-Catherine S. A Blind Spot in girls' education: Menarche and its webs of exclusion in Ghana. Journal of International Development. 2017; 10(1): 17-29.

28- Madden R, Cox B. What makes a good audio drama? Journal 2020.

Available from: https://www.reddit.com/r/ audiodrama/comments/75q1im/what_m akes_a_good_audio_drama.

29- Fryer L, Pring L, Freeman O. Audio drama and the imagination the influence of sound effects on presence in people with and without sight. Journal of Media Psychology Theories Methods and Applications. 2013; 25(2):6571.DOI: $\quad 10.1027 / 1864-1105 / \mathrm{a} 000084$. Available from https://www. researchgate.net/publication/236216773 Audio_Drama and the Imagination The_Influence_of_Sound_Effects_on_P resence_in_People_With_and_Without Sight.

30- Fryer L. The independent audio describer is dead: Long Live Audio Description!.2018.Available from: https://www.researchgate. net/ publication/329091708_The_Independe nt_Audio_Describe

31-Kanmani A, Ravisankar F. Prevalence of menstrual problems and treatment seeking behavior: A study among visually challenged women. Indian Journal of Adolescents Med Health. 2013; 51(1):7-11.

32- Sanctis V, Soliman A, Elsedfy H, Soliman NA, Elalaily R, Kholy M. Dysmenorrhea in adolescents and young adults: A review in different countries. Acta Biomed. 2016;87(1):9-18.

33-Habibi N, Huang M, Gan W, Zulida R, Safavi SM. Dysmenorrhea and 
factors associated with its intensity among undergraduate students: a crosssectional study. Pain Manag Nurs. 2015; 16(6): 855-861.

\section{4- Acheampong K, Awuah D, Ganu D,} Appiah S, Pan X, Kaminga A, et al. Prevalence and predictors of dysmenorrhea: Its effect, and coping mechanisms among adolescents in Shai Osudoku District, Ghana. Obstetrics and Gynecology International.2019. Available from: https://doi.org/ $10.1155 / 2019 / 5834159$.

35- Mazur I. Visual Impairment \& Blindness (J VISUAL IMPAIR BLIN). 2020.DOI: 10.1007/978-3-030-421052_12.Available from:

https://www.researchgate.net/publication/3 44339303_Audio_Description_Concept s_Theories_and_Research_Approaches 36- Ramos M.The emotional experience of films: Does Audio Description make a difference?. 2015 .DOI: 10.1080/ 13556509.2014.994853.Available from:https://www.researchgate.net/publ ication/276089642_The_emotional_exp erience_of_films_does_Audio_Descript ion.

37- Samah Ahmed Mohamed Sakr. Breast Self- Examination Compliance among Visually Impaired Adolescent Girls: A Nursing Interventional Study. 2019.
38- Jha S. Effectiveness of planned audio teaching program on menstrual hygiene in terms of knowledge among visually challenged adolescent girls, in selected blind school. West Bengal. 2018; 06(10):. DOI: Available from:http://dx. doi.org/10.18535/ijsre/v6i7.04

41- Nag U, Kodali M. Effect of Yoga on primary dysmenorrhea and stress in medical students. IOSR Journal of Dental and Medical Sciences (IOSRJDMS) 2013; 4(1): 69-73 . Available from: www.iosrjournals.org

39- Beena K. Effect of instructional programme on knowledge of adolescent girls regarding reproductive health. International Journal of Nursing Education. 2016; 8(1): 68-71.

43- Mekonnen F. Knowledge and practice of menstrual hygiene awareness: Control and prevention. BMJ. 2016; 7(1): 6-7. Available from: http://www.menstruationresearch.org.

40- Das p, Baker K, Dutta A, Swain T, Sahoo S, Das B, et al. Menstrual hygiene practices: Wash access and the risk of urogenital infection in women from Odisha, India. 2015. doi: 10.1371/journal.pone.0130777 Available from: https://www.ncbi.nlm.nih.gov/pmc/artic les/PMC4488331 
41- Deshpande T, Patil S,Gharai S, DurgawaleP. Menstrual hygiene among adolescent girls - A study from urban slum area. 2018. doi: 10.4103/jfmpc.jfmpc_80_18.

42- Jeyanthi P. Effectiveness of audio drama on menstrual hygiene and management of minor ailments of menstruation upon knowledge and practice among visually challenged girls. Published Master Thesis, Tamilnadu Dr.M.G.R., Medical University, 2017. Available from: https://core.ac.uk/display/235663899

43- El-Kurdy R, Fadel E, Elsayed A. Effect of structured audio educational sessions on visually challenges adolescent school-girls' knowledge and practices regarding menstruation. International Journal of Novel Research in Healthcare and Nursing. 2020; 7(1): 497-509. Available from: www.noveltyjournals.com. 